\title{
Patiwangi Dalam Upacara Perkawinan di Kota Denpasar
}

\author{
Ni Luh Gede Hadriani \\ Sekolah Tinggi Agama Hindu Negeri Mpu Kuturan Singaraja \\ luhgedehadriani@gmail.com
}

\begin{abstract}
Patiwangi in marriage ceremonies between clans has been banned by the government because it was not in accordance with human values. However, until now, patiwangi, there are still Hindu communities in Denpasar who carry out this activity. This study aims to examine the reasons for implementing patiwangi in among the clan smarriage ceremonies and their implications for the lives of the bride and groom and their families. This research includes qualitative research, data collection is done through observation, interviews and documentation. The research data were analyzed descriptively interpretively through three cycles, data reduction, data presentation, and drawing conclusions. The results showed that the patiwangi ceremony was still carried out among the clasn marriage ceremonies by the Hindu community in Denpasar City because they followed the tradition, hoping to create happiness, tranquility, and harmony in family relationships. Patiwangi in among the clans marriage has implications for the religious, socio-cultural, and psychological life of the bride and groom.
\end{abstract}

Keywords: Patiwangi; Wedding Ceremon

\begin{abstract}
Abstrak
Upacara patiwangi dalam pelaksanaan perkawinan antar wangsa sudah dilarang oleh pemerintah karena tidak sesuai dengan nilai-nilai kemanusiaan. Akan tetapi patiwangi sampai saat ini, masih ada masyarakat Hindu di Kota Denpasar yang melaksanakan. Penelitian ini bertujuan untuk mengkaji alasan dilaksanakannya patiwangi dalam upacara perkawinan antarwangsa serta implikasinya terhadap kehidupan mempelai dan keluarganya. Penelitian ini termasuk penelitian kualitatif, proses pengumpulan data melalui wawancara, observasi dan dokumentasi. Data penelitian dianalisis secara deskriptif interpretatife melalui tiga siklus, reduksi data, penyajian data, dan penarikan simpulan. Hasil penelitian didapatkan bahwa upacara patiwangi masih dilakukan dalam upacara perkawinan antar wangsa oleh masyarakat Hindu di Kota Denpasar karena mereka mengikuti tradisi, mengharapkan terciptanya kebahagiaan, ketenangan, dan keharmonisan dalam hubungan keluarga. Patiwangi dalam perkawinan antar wangsa berimplikasi terhadap kehidupan beragama, sosial budaya, dan psikologis pasangan pengantin.
\end{abstract}

Kata Kunci: Patiwangi; Upacara Perkawinan

\section{Pendahuluan}

Patiwangi dalam upacara perkawinan yang dilaksanakan antar wangsa dalam masyarakat yang bragama Hindu di Bali sudah dihapus sejak tahun 1951, namun sampai saat sekarang patiwangi tetap dilaksanakan dalam perkawinan antar wangsa di Bali. Patiwangi hampir setiap tahun dilakukan pada kabupaten yang ada di Bali, termasuk di Kota Denpasar, padahal Kota Denpasar merupakan barometer terhadap perubahan yang terjadi di Bali karena merupakan ibu kota Provinsi Bali. Dilaksanakannya patiwangi dalam upacara perkawinan menimbulkan keprihatinan dalam masyarakat hindu di Bali. 
Patiwangi bertentangan dengan ideologi Pancasila, terutama Sila pertama, sila ini mengajarkan semua manusia memperoleh kedudukan yang sama di hadapan Tuhan, demikian juga sila kedua yang mengajarkan setiap manusia mendapatkan perlakuan adil tanpa memandang ras, wangsa, suku, dan jenis kelamin. Patiwangi juga bertentangan dengan peraturan perundang- undangan yang berlaku, akan tetapi sampai sekarang patiwangi dalam perkawinan antar wangsa masih saja dilaksanakan pada upacara perkawinan Umat Hindu di Kota Denpasar. Secara sosiologis ada kegagalan pemuka agama/adat dan pemerintah dalam mengubah prilaku masyarakat sesuai dengan ketentun yang berlaku. Buktinya sampai saat ini secara empiris patiwangi masih dilaksanakan dalam upacara perkawinan antar wangsa di kalangan umat Hindu di Kota Denpasar. Akibatnya, masyarakat Hindu di Bali timbul pro kontra dalam menyikapi pelaksanaan patiwingi tersebut, artinya ada masyarakat yang setuju ada pula masyarakat yang tidak setuju (Krepun, 2004). Penelitian yang dilakukan oleh Yudha Triguna (1997), Lestari (2013), Putra (2013), dan Sadnyini (2015), adalah penelitan yang terkait dengan wangsa, namun substansi penelitian yang dilakukan oleh Yudha Triguna, Lestari, Komang Putra, dan Sadnyini tidak sama dengan substansi permasalahan penelitian yang dilakukan peneliti. Dikatakan tidak sama karena penelitian ini fokus mengkaji patiwangi dalam perkawinan antar-wangsa dalam masyarakat Hindu di Kota Denpasar.

Berdasarkan keprihatinan filosofis, yuridis, dan sosiologis tersebut, terlihat jelas adanya pro kontra dalam masyarakat yang beragama Hindu di Bali terhadap patiwangi dalam perkawinan antar wangsa di Kota Denpasar. Hal ini ada kesenjangan atau antara harapan dan kenyataan dari patiwangi dalam perkawinan antar wangsa di Kota Denpasar. Oleh krenanya penelitian yang mendalam tentang patiwangi dalam upacara perkawinan antar wangsa di Kota Denpasar, sangat perlu dan menarik dilakukan.

\section{Metode}

Penelitian tentang patiwangi dalam upacara perkawinan antar wangsa pada masyarakat Hindu di Kota Denpasar ini, dirancang dengan langkah-langkah penelitian kualitatif. Hal tersebut dilakukan karena dalam penelitian ini diusahakan dipahami fenomena-fenomena sosial religius yang terkait dengan patiwangi di Kota Denpasar. Pengumpulan data didapatkan melalui wawancara dengan narasumber yang mengetahui permasalahan, dan studi dokumen. Observasi dilakukan terhadap kehidupan pasangan keluarga yang telah melakukan patiwangi dalam upacara perkawinannya, baik menyangkut kehidupan agama, sosial, maupun budayanya. Observasi yang dilakukan adalah observasi nonpartisipatif karena peneliti dalam proses pengamatan tidak terlibat secara langsung dalam upacara patiwangi tersebut. Wawancara dilakukan dengan para informan yang dipandang relevan dan mengetahui benar tentang patiwangi dalam upacara perkawinan antar wangsa, khususnya yang terkait dengan alasan mengapa patiwangi tetap dilaksanakan, proses patiwangi, dan implikasi patiwangi terhadap kehidupan sosial budaya masyarakat. Teknik dalam menentukan informan dengan cara bola bergulir (snowball). Hal yang pertama dilakukan dengan menentukan informan kunci yang selanjutnya dimintakan informasi untuk memperoleh informan selanjutnya. Informan kedua kembali diminta pendapat mengenai informan berikutnya. Teknik ini terus dilakukan sampai informasi dianggap cukup untuk melakukan tahap penulisan. Informan kunci yang ditetapkan adalah Bendesa Adat di tiap-tiap desa pakraman yang diteliti, dari bendesa pakraman diminta informasi tentang informan selanjutnya yang akan diwawancarai. Studi dokumen dilakukan demi memperoleh berhubungan dengan patiwangi dalam upacara perkawinan antar wangsa. Studi dokumen meliputi jurnal-jurnal, buku-buku, peraturan-peraturan, dn laporan kegiatan.

Data penelitian ini dianalisis secara kualitatif, selanjutnya diuraikan dengan metode analisis deskriptif interpretative. Proses analisis data dilaksanakan melalui beberapa langkahlangkah diantaranya: reduksi data yaitu suatu proses yang dilaksanakan dengan pemilihan data, setelah itu baru penyajian data, penarikan simpulan, dan verifikasi terhadap data tersebut. Proses ini berlangsung terus-menerus sampai tuntas. 


\section{Hasil dan Pembahasan}

\section{Alasan dilaksanakannya Patiwangi dalam Upacara Perkawinan Antar Wangsa di Kota Denpasar}

Upacara Patiwangi dalam perkawinan antar wangsa sampai sekarang masih dilaksanakan oleh Masyarakat Kota Denpasar salah satu alasannya adalah karena masyarakat taat mengikuti tradisi yang ada di desa pakraman, yang didasari oleh kuno (purwa) dresta dan loka dresta. Anak Agung Ngurah Oka informan yang diwawancarai pada tanggal 2 Februari tahun 2017 menyampaikan sebagai berikut.

Ketika ada warga di desa pakraman kami yang melakulan perkawinan antar wangsa, maka patiwangi dilaksanakan sebagai rangkaian dalam upacara perkawinan. patiwangi ini dilaksanaka di Pura Desa. Upacara ini dilakukan karena semua ini memang merupakan tradisi atau aturan-aturan yang sudah berlaku sejak jaman dahulu, kemudian aturan - aturan tersebut di desa kami dipakai pedoman dalam kehidupan masyarakat di desa kami.

Dari penyampain informan tersebut di atas, bahwa patiwangi dilaksanakan dalam upacara perkawinan antar wangsa di Kota Denpasar karena masyarakat mengikuti tradisi yang ada di desa pakraman. Masyarakat masih tunduk dan patuh pada tradisi yang diwarisi dan disepakati untuk tetap dilaksanakan (loka dresta). Perilaku dan tindakan masyarakat Hindu di Kota Denpasar yang melaksanakan patiwangi dalam upacara perkawinan antar-wangsa menunjukkan bahwa masyarakat masih memiliki adaptasi yang kuat terhadap tradisi yang hidup dan terus berkembang pada masyarakat adat yang diwarisi. Artinya, dalam kehidupan masyarakat senantiasa diarahkan untuk mencapai keharmonisan dan kebersamaan karena dalam sistem sosial tingkat solidaritas merupakan satu keharusan, dengan tujuan untuk menciptakan kerelaan bekerja sama yang harus dipertahankan (Nazsir, 2008). Hal itu dimaksudkan agar sistem sosial (desa pakraman) itu dapat berperan secara efektif. Karena dalam desa pakraman tingkat kebersamaan antar krama merupakan hal yang mutlak untuk menjadi kebutuhan sehingga menjamin adanya ikatan emosioanal dengan sistem sosial (desa pakraman).

Patiwangi dilaksanakan dalam masyarakat Hindu di Kota Denpasar semata-mata untuk menciptakan keharmonisan dalam kehidupan pasangan mempelai dalam mengarungi kehidupan rumah tangganya. Kenyataan di atas menunjukkan bahwa masyarakat Hindu Bali kuat kepercayaannya terhadap tradisi yang diwarisi dan sangat susah dihapus karena sudah mengakar dalam kehidupan masyarakat. Artinya, patiwangi dilaksanakan dalam masyarakat Hindu di Kota Denpasar semata-mata karena mengikuti tradisi yang diwariskan. Disamping itu juga untuk menciptakan keharmonisan dalam kehidupan pasangan mempelai dalam mengarungi kehidupan rumah tangganya. Selain mengikuti tradisi dan mengharapkan adanya keharmonisan dalam hubungan keluarga, patiwangi dilaksanakan oleh masyarakat Hindu yang melangsungkan perkawinan beda wangsa di Kota Denpasar adalah juga karena mengikuti petunjuk sulinggih karena ikatan siwa sisya, masyarakat masih sangat percaya tentang petunjuk- petunjuk seorang sulinggih. Yoga Segara (2015) dalam hasil penelitiannya secara detail menyampaikan bahwa patiwangi dilakukan karena atas petunjuk sulinggih. Kepercayaan semacam ini masih berlaku di daerah lain di Bali. Jadi untuk keselamatan dan keharmonisan wangsa perempuan yang dianggap lebih tinggi (tri wangsa) harus disamakan dengan wangsa laki-lakinya yang lebih rendah (jaba wangsa).

\section{Pelaksanaan Patiwangi dalam Perkawinan Antar Wangsa di Kota Denpasar}

Tujuannya upacara patiwangi adalah menurunkan wangsa perempuann sehingga sama dengan wangsa laki-laki. Apabila upacara patiwangi tidak dilaksanakan, hal tersebut akan menimbulkan musibah dan mempelai perempuan dianggap cemer karena melayani wangsa yang lebih rendah. 
Upacara Patiwangi ini dilaksanakan di Pura Desa, dengan prosesi, kedua mempelai mengitari Pura Desa sebanyak tiga kali. Pura Desa (Bale Agung) dipilih sebagai tempat upacara patiwangi karena masyarakat memandang bahwa Pura Desa (Bale Agung) merupakan tempat berstananya Ida Betara Brahma. Di hadapan Ida Betara Brahma upacara patiwangi dilaksanakan karena masyarakat memandang bahwa Betara Brahma adalah dewa pencipta. Dalam konteks upacara patiwangi mempelai perempuan dipandang baru lahir kembali pada keluarga mempelai laki-laki sehingga kedudukannya menjadi sama dengan mempelai laki-laki. Dipercayai jika kedudukan mempelai sudah sama, proses penyesuaian mempelai perempuan dengan mempelai laki-laki dan keluarganya akan bisa lebih cepat diwujudkan. Jika penyesuaian sudah dapat dilakukan, perjalanan dalam menempuh bahtera rumah tangga akan lebih harmonis dan dapat berjalan sejalan dengan tujuan perkawinan yaitu menciptakan keluarga yang bahagia.

Koentjaraningrat (2009) mengatakan bahwa sistem dan peralatan ritus serta upacara merupakan komponen yang sangat penting dalam kehidupan beragama. Lebih lanjut Koentjaraningrat mengatakan bahwa dalam ritual keagamaan digunakan berbagai macam sarana seperti tempat pemujaan. Patiwangi dalam perkawinan antar wangsa di Kota Denpasar menggunakan berbagai macam sarana upakara seperti Banten byakaonan ini digunakan sebagai pendahuluan dalam melaksanakan upacara yang bertujuan memberikan korban kepada bhuta kala atau unsur kekuatan alam yang berada di tempat upacara agar tidak mengganggu upacara. Banten Suci yang digunakan sebagai pesaksi. Banten Prayascita untuk pembersihan bangunan pelinggih tempat dilaksanakannya upacara atau sebelum upacara patiwangi dilaksanakan semua bangunan pelinggih dibersihkan. Setelah dilaksanakan pembersihan bangunan pelinggih kedua mempelai diupacarai dengan Banten Prayascita. Banten caru siap brumbun yang digunakan dalam upacara patiwangi merupakan salah satu upacara bhuta yadnya. Banten Upasaksi mangku dan Banten pengulapan yang menggunakan ulam bebek. Banten pengulapan diisi lidi tiga batang yang diikat dengan benang, endong tiga muncuk, dan sanggah urip mepayas

Pelaksanaan Patiwangi diawali dengan Jero Mangku Pura Desa melakukan pemujan untuk memohon keselamatan kepada Dewa Brahma, kemudian dilanjutkan dengan nguningayang banten byakaonan dan banten prayascita, banten byakaoan, dan prayascita yang diberikan kepada kedua mempelai supaya kedua mempelai bersih atau tidak leteh lagi. Fungsi penyucian dikaitkan dengan adanya unsur air suci atau tirta dalam sarana ritual. Makna penyucian yang bernilai tinggi terdapat pula dalam banten dan rasa tulus ikhlas dalam menyisihkan sebagian miliknya untuk dipersembahkan kepada Tuhan (Suarsi, 2004).

Rangkaian upacara berikutnya adalah Pemangku Pura Desa nguningang banten caru, pengulapan, dan durmangala, sebagai pembersihan areal pura. Setelah Pemangku Pura Desa selesai nguningang banten mecaru, pengulapan, dan durmangala dilanjutkan dengan upacara patiwangi. Di depan pelinggih Pura Desa (Pura Bale Agung) pemangku nguningang ke hadapan Ida Bhatara Brahma adanya upacara patiwangi. Tujuan acara nguningang kehadapan Ida Bhatara Brahma adalah untuk menyejajarkan wangsa mempelai perempuan dengan mempelai laki-laki. Dengan menggunakan sarana yaitu tiga lidi ron yang diikat benang tri datu dan daun endong dalam rangkain upacara patiwangi memiliki makna simbolis Dewa Tri Murti. Di pihak lain daun endong merah melambangankan Dewa Brahma sebagai dewa pencipta. Pada upacara patiwangi mempelai perempuan dianggap dilahirkan kembali di keluarga lakilaki, agar pasangan pengantin memiliki kedudukan yang sama. Setelah upacara patiwangi tersebut selesai, kemudian dilanjutkan dengan acara tebah bahasa menggunakan bahasa sesuai dengan wangsa suaminya. Kemudian banten pengurip mepayas (sangga urip) sebagai lambang pengawak mempelai perempuan dibawa pulang, dan ditaruh di atas tempat tidur mempelai selama tiga hari. Dengan menyejajarkan wangsa mempelai perempuan dan mempelai lakilaki diharapkan kedua mempelai menjadi keluarga yang harmoni dalam menempuh kehidupan berumah tangga. Setelah upacara patiwangi selesai, barulah dilaksanakan upacara pawiwahan. 
Waktu pelaksanaan upacara pawiwahan ini didasari atas padewasan yang telah disepakati keluarga mempelai laki-laki. Upacara pawiwahan bagi pasangan beda wangsa ini, dilaksanakan sesuai dengan upacara pawiwahan yang dilakukan umat Hindu pada umumnya dan dresta ditiap-tiap desa pakramannya.

\section{Implikasi Patiwangi Terhadap Kehidupam Beragama dan Sosial Budaya Pasangan Pengantin di Kota Denpasar}

Upacara patiwangi yang dilaksanakan dalam upacara pekawinan antar-wangsa di Kota Denpasar berimpliksi terhadap kehidupan beragama, sosial budaya dan psikologis bagi pasangan mempelai. Implikasi dalam kehidupan beragama terhadap pasangan mempelai adalah tidak dizinkan mempelai perempuan mempersembahkan sendiri sesaji di merajan asalnya, tidak diperbolehkan mejauman membawa tipat bantal dan mepamit pada saat perkawinannya, terkadang sampai lebih dari satu tahun pasangan perkawinan antar-wangsa ini belum diterima oleh keluarganya. orang tua dan keluarga mempelai perempuan tidak ikut menyaksikan upacara perkawinan anaknya. Sampai sekarang masyarakat Hindu di Kota Denpasar masih melakukan upacara patiwangi dalam perkawinan antar wangsa. Artinya masih ada anggapan bahwa perkawinan antar wangsa tersebut dapat menimbulkan disharmoni hubungan antara pasangan mempelai dan keluarganya karena mereka berasal dari wangsa yang berbeda. Dari hasil penelitian dilakukan ditemukan juga beberapa implikasi (dampak ikutan) dari perubahan status wangsa terhadap kehidupan sosial budaya pasangan mempelai dan keluarganya. Terjadinya perubahan etika cara berbahasa, cara duduk, dan cara makan yang harus dilakukan oleh mempelai perempuan terhadap keluarga asalnya. Dalam hal ini mempelai perempuan masih merasakan adanya tekanan psikologis dalam dirinya.

Patiwangi yang mengubah wangsa mempelai perempuan mengikuti wangsa laki-laki berimplikasi terhadap perubahan etika cara berbahasa, cara bertutur kata atau berbahasa mempelai perempuan terhadap keluarga asalnya. Hal tersebut terjadi karena adanya struktur sosial dalam kehidupan masyarakat di Bali membawa konsekuensi pada sistem komunikasi antara personal yang berasal dari wangsa yang berbeda. Dalam hal ini kedudukan mempelai perempuan dianggap tidak sederajat lagi dengan wangsa asalnya karena sudah dipatiwangi atau diturunkan wangsanya karena mengikuti wangsa suaminya yang dianggap lebih rendah. Dwipayana (2001) mengatakan bahwa adanya struktur sosial dalam kehidupan masyarakat di Bali membawa konsekuensi pada sistem komunikasi antar personal yang berasal dari wangsa yang berbeda.

Semakin jauh tinggi rendahnya wangsa, semakin tempak struktur kebahasaan yang digunakan oleh kedua belah pihak. Oleh karena itu, dituntut harus mengetahui kedudukan masing-masing sehingga terhindar dari pelanggaran-pelanggaran yang menyebabkan ketika pulang ke rumah asalnya mempelai perempuan, harus menggunakan sor singgih basa atau bahasa halus terhadap keluarganya, baik kepada orang tuanya maupun saudara-saudaranya. Ia tidak boleh lagi menggunakan bahsa seperti ketika masih gadis. Ia tidak boleh memanggil adikadiknya dengan menyebutkan namanya. Biasanya panggilan diawali dengan menyebutkan ratu atau atu (panggilan untuk tri wangsa dari jaba wangsa), terutama di hadapan umum. Perubahan status wangsa juga berimplikasi juga terhadap etika terkait dengan jamuan makan. Ketika ke rumah keluarga asalnya mempelai perempuan tidak masih sebebas mengambil dan memperlakukan saudara-saudaranya seperti ketika masih gadis dalam soal makan. Misalnya, mempelai perempuan tidak boleh lagi saling menyuapi dengan saudara-saudaranya. Saudaranya termasuk adik atau keponakannya yang umurnya lebih kecil tidak boleh lagi memakan makanan carikan (sisa makanannya) karena sudah berbeda wangsa cemar atau "leteh" (Dwipayana 2001).

Kenyatan ini berimplikasi terhadap psikologis terhadap pasangan mempelai terutama mempelai perempuan. Dalam hal ini mereka merasa disisihkan dari keluarganya, dan merasa kehilangan sebagian jati dirinya. Terebih lagi setelah mempelai perempuan melaksanakan 
upacara patiwangi, mempelai perempuan dikeluarkan dari golongan wangsanya dan tidak berhak lagi atas gelar yang disandang sebelumnya. Oleh karena itu, beberapa keharusan dan larangan bagi pasangan pengantin perempuan harus dilakukan, seperti etika berbahasa, etika pergaulan, dan etika makan, karena mempelai perempuan sudah masuk mengikuti wangsa suaminya, ia tidak boleh lagi memanggil orang tuanya dengan panggilan aji dan biang seperti panggilan ketika ia masih gadis. Selain itu juga tidak boleh memanggil nama adik-adiknya seperti sebelum ia kawin dengan seseorang dari kalangan sudra wangsa. Ketika ia pulang ke rumah asalnya wajib menggunalkan bahasa halus kepada keluargananya, itu terjadi karena kepulangan mereka dianggap sebagai tamu bukan bagian dari keluarganya. Sebelum menikah, dalam kehidupan sehari-hari mempelai perempuan menggunakan bahasa halus dengan kekuarganya. Sedangkan menggunakan bahasa biasa dengan orang yang berkasta lebih rendah. Beban psikologis sebenarnya sudah ada pada mempelai perempuan ketika ia masih gadis atau pada masa pacaran karena ia dilarang oleh orang tuanya untuk kawin dengan wangsa yang berbeda apalagi dengan wangsa yang lebih rendah karena dianggap leteh atau panes.

\section{Kesimpulan}

Patiwangi tetap dilaksanakan dalam upacara perkawinan antar-wangsa oleh masyarakat Hindu yang berada di Kota Denpasar karena mengikuti tradisi yang diwarisi oleh masyarakat sejak zaman dahulu yang tidak berani dilanggar, dengan tujuan agar mereka bisa hidup bahagia, tenang, dan harmonis dalam hubungan antara pasangan mempelai dan keluarganya. Pelaksanaan upacara Patiwangi terlebih dahulu matur piuning di Pura Bale Agung dengan maksud memohon doa kepada Batara Brahma guna memohon agar wangsa mempelai perempuan sejajar dengan wangsa mempelai laki-laki. Patiwangi dalam perkawinan antarwangsa dalam masyarakat Hindu di Kota Denpasar berimplikasi terhadap kehidupan beragama, sosial budaya, dan psikologi pasangan mempelai.

\section{Daftar Pustaka}

Arikunto. (2002). Prosedur Penelitian Suatu Pendekatan Pratek. Jakarta: PT Rineka Cipta.

Artadi, I K. (1980). Hukum Adat Bali dengan Aneka Masalahnya. Denpasar: Pustaka Bali Post.

Bungin, B. (2003). Analisis Data Penelitian Kualitatif, pemahaman Filosofis dan Metodologis kearah Penguasaan Model Aplikasi. Jakarta: PT Raja Grafindo Persada.

Dwipayana, A. (2001). Kelas dan Kasta, Pergulatan Kelas Menengah Bali. Yogyakarta: Yayasan Adikarya Ikapi dan The Ford Foundation.

Gelgel, I P. (2013). Hukum Perkawinan Hindu. Denpasar: Pascasarjana Universitas Hindu Indonesia Bekerja sama dengan Widya Dharma.

Ihromi. (2000). Penghapusan Diskriminasi Wanita. Bandung: Alumni.

Kamanto, S. (2004). Pengantar Sosiologi. Jakarta: Fakultas Ekonomi UI.

Karmini, N. W. (2015). Perempuan Hindu dalam Pasungan Tradisi. Denpasar: Sari Kahyangan Indonesia.

Kerepun, M. K. (2007). Mengurai Benang Kusut Kasta Membedah Kiat Pengajegan Kasta di Bali. Denpasar: PT. Empat Warna Komunikasi.

Koentjaraningrat. (1970). Manusia dan Kebudayaan di Indonesia. Jakarta: Djambatan.

Lestari, I. A. M. dkk. (2013). Implikasi Perkawinan Beda Kasta dalam Persfektif Hukum, Sosial, Budaya dan Religius di Banjar Brhamana Bukut, Kec Bangli Kab. Bangli: Jurnal Undiksha

Mantra, I. B. (1996). Landasan Kebudayaan Bali. Denpasar: Yayasan Dharma Sastra.

Pudja. G. (1978). Manawa Dharmacastra (Manu Dharmasastra). Jakarta: Direktorat Jenderal Bimas Hindu.

Putra, M. (1983). Mejejahitan. Denpasar: Pemda Bali. 
Rahardjo, S. (2007). Biarkan Hukum Mengalir (Catatan Kritis Tentang Pergulatan Manusia dan Hukum). Jakarta: Penerbit Buku Kompas.

Ritzer, G. \& Douglas J G. (2003). Teori Sosiologi Modern. Jakarta: Prenada Media

Sadnyini, I. A. (2015). Disertasi, "Dinamika Sanksi Hukum Adat dalam Perkawinan antar Wangsa di Bali". Universitas Udayana

Suarsi, S. (2004). Fungsi Kearifan Lokal dalam Meningkatkan Kualitas Sumber Daya Manusia. Denpasar: Balai Kajian Sejarah dan Nilai Tradisional Denpasar.

Titib, I M. (2000). Teologi dan Simbol-Simbol dalam Agama Hindu. Surabaya: Paramita.

Triguna, I. B. G. Y. (1997). Mobilitas Kelas, Konflik dan Penafsiran Kembali Simbolisme Masyarakat Bali, Disertasi, Universitas Padjadjaran Bandung.

Wiana, K. \& Raka Santri. (2005). Kasta dalam Hindu Kesalahpahaman Berabad-abad. Denpasar: Yayasan Dharma Naradha.

Yoga, S. (2015). Perkawinan Nyerod Kontestasi, Negoisasi, dan Komodifikasi di atas Mozaik Kebudayaan Bali. Jakarta: PT Saadah Pustaka Mandiri. 